\title{
An Experiential Learning Approach To Teaching Social Entrepreneurship, Triple Bottom Line, And Sustainability: Modifying And Extending Practical Organizational Behavior Education (PROBE)
}

Michael J. Gundlach, Ph.D., California State University, Chico, USA Suzanne Zivnuska, Ph.D., California State University, Chico, USA

\begin{abstract}
When teaching social entrepreneurship and sustainability, using an experiential learning approach can be more effective than a traditional lecture approach. Social and environmental entrepreneurs often have a deep passion for their work that is important for students to develop early in their careers. Experiential learning enables students to create and experience this passion for themselves, thereby preparing them with the motivational and emotional resources they may need to be successful in the future. We introduce Practical Organizational Behavior Education (PROBE) as one way of helping students develop this passion. PROBE was originally developed as a service-learning project for an undergraduate course in organizational behavior at a very small, private university. However, in this manuscript, we show how PROBE can be modified and extended to effectively teach business students about triple bottom line concepts, sustainability, and social entrepreneurship at the undergraduate and MBA levels within a large, public university system. We provide practical suggestions for instructors interested in implementing this approach in a broad variety of settings.
\end{abstract}

Keywords: Experiential learning, triple bottom line, social entrepreneurship, sustainability

\section{INTRODUCTION}

1 nteresting, dynamic topics such as social entrepreneurship, triple bottom line concepts, and sustainability, often come across to students as relatively dry and overly conceptual when taught using traditional pedagogical approaches. We seek to breathe new life into these concepts by actively engaging students in these topics by modifying and extending a documented pedagogical technique called Practical Organizational Behavior Education (PROBE). This powerful experiential-learning technique makes course content related to the triple bottom line, sustainability, and entrepreneurship come alive for students and can result in a very rewarding experience for instructors.

Our focus is on the application of PROBE to triple bottom line concepts and social entrepreneurship. The triple bottom line is a particularly salient concept in today's organizations, when stakeholders are increasingly holding organizations accountable for not only achieving financial success, but also for their social and environmental impacts (e.g., Borgaza \& Defourny, 2001; Dees, 1998; Paton, 2003; Rice, 1993; Tracey \& Phillips, 2007). In particular, we discuss how we have modified the original PROBE approach to teach business students to discover and implement financially profitable business ventures that also contribute to solving social and 
environmental problems. This teaching approach is appropriate for courses in general management, entrepreneurship and social entrepreneurship, sustainability, and MBA courses in management. We hope to provide readers with a thorough grounding in a technique that will allow them to easily incorporate this methodology into their management curriculum.

To this end, we have organized this manuscript in five sections as follows. Firstly, we introduce the traditional PROBE technique. Secondly, we explain how PROBE can be modified to teach triple bottom line concepts. Thirdly, we provide real-world examples of student projects that have resulted in triple bottom line success in three different settings (undergraduate courses in a small, private university; undergraduate courses in a large, public university; and MBA courses in a large, public university). Fourthly, we address course assessment issues. Lastly, we offer concluding thoughts and discuss future directions for both teaching and research.

\section{WHAT IS PROBE?}

PROBE was developed by Nirenberg (1994) as a teaching methodology requiring students to be experientially involved in their learning process at a small, private university. Nirenberg's work was a reaction to criticism that business school curriculums were overly theoretical and that practical learning experiences would better prepare students for their future careers. Not surprisingly, these criticisms have held true (Cheit, 1985; Gioia \& Corley, 2002; Hayes \& Abernathy, 1980; Linder \& Smith, 1992; Mintzberg \& Gosling, 2002; Pfeffer \& Fong, 2002; Porter \& McKibbin, 1988). In response, many business schools are re-designing their curriculums to focus on more action-oriented, real world learning than ever before.

In particular, introductory courses in general management and organizational behavior are often targeted for such practical curriculum changes. General management courses are usually designed as a broad introduction to the field of management, focusing on the coordination of work activities with an eye to efficiency and effectiveness (Robbins \& Coulter, 2007). Organizational behavior, a sub-field in the management arena, refers to the field of academic inquiry concerned with the actions and behaviors of people at work (Robbins \& Coulter, 2007). Almost all business schools will offer one of these courses or a very similar course as part of their required curriculum. These courses are often required at the undergraduate level and may also be found at the graduate level (e.g., in MBA curricula).

PROBE was developed with the intent of bringing a more practical, real-world learning experience to undergraduate students in organizational behavior courses. PROBE "combines an experiential approach with a student-centered (self-directed) methodology that allows students of all cultures and backgrounds to create theory from their experience..." (Nirenberg, 1994, p. 325). More than just an assignment, PROBE is an over-arching pedagogical methodology that provides students with experiential educational opportunities which supplement, or even replace, a traditional lecture and textbook approach. As Nirenberg explains, "[i]n a radical departure from standard techniques, the author developed a student-centered learning experience that involves creating actual organizations that carry real financial and emotional risk for the students" (1994, p. 325). Therefore, although it was originally designed to replace traditional course delivery methods in organizational behavior courses, PROBE is a very flexible model that can be adapted to the needs of different instructors in variety of disciplines. In particular, we have found it very effective at engaging students in any courses covering triple bottom line concepts.

As originally developed by Nirenberg (1994), PROBE offers students the opportunity to plan, implement, and evaluate a real business venture within just one semester. In its original incantation, small groups of randomly assigned students were required to develop and implement a business plan for providing any service or developing a product. They assumed financial responsibility for their "organization" by generating and managing funds either through their own investment, by finding financial backers (e.g., corporate sponsors), or by any other means they developed (e.g., by selling advertisements to participating organizations/stakeholders). Because this project was developed for an organizational behavior course open to all business and non-business majors from across the university, students were allowed to choose to run either profit or non-profit ventures.

To support students in this endeavor, classroom time was structured to involve more than a traditional lecture format, including time for organizational updates (i.e., progress reports from student teams). This time was 
intended to be for problem-solving sessions, where students were encouraged to discuss their challenges and help each other apply course material to find effective solutions to those problems. Nirenberg (1994) recommended that in the beginning of a course, these problem-solving discussions should be instigated by the instructor, and that as the semester progresses, the student teams themselves assume that responsibility using class readings as their jumpingoff point. Thus, the responsibility for learning rests greatly on the shoulders of students. When facilitated well, these team updates can help the class as a whole build a culture of teamwork and collegiality that is generally not found in more traditional classrooms. Nirenberg (1994) also noted that this informal, self-directed teaching must be accompanied by discussion and application of relevant course material and concepts. In fact, just like in a traditional classroom, the majority of class time should be used to discuss readings related to the topic area(s) of the course.

In addition to guiding classroom activities, the instructor primarily acts as a facilitator who observes the students' organizations and acts as a resource for them when they confront serious difficulties. The instructor should help the student organizations reflect on the strategies, decisions, and interpersonal processes that have led to their successes and failures. By using class material to analyze these instances, a powerful student-centered learning experience takes place.

In our experience, using this traditional PROBE approach as a teaching tool in organizational behavior courses at a small (total enrolment less than 2000) private institution was quite successful. The PROBE approach is rich with learning opportunities for students and instructors alike. Additionally, PROBE has been found to be effective with relatively homogeneous groups of students as well as in more culturally diverse classroom settings. For example, the PROBE approach worked well with teams of upper-middle class students from the U.S. who were studying abroad, as well as with culturally diverse teams where each team member had a different nationality. At the same time, however, we noted that our initial experiences with PROBE occurred in a relatively sheltered university environment with small class sizes (20-30), where the majority of students were studying abroad and most were from financially privileged backgrounds. Additionally, the PROBE project in this setting had grown into a well-established hallmark of the entire university's culture. Students across campus looked forward each semester to the many projects and events run by student teams, and participation in them was extremely high. Additionally, because students enjoyed the project so much and excitement about it was high, the organizational behavior course became one of the most popular courses across the campus.

Based on our teaching success with the PROBE technique in this context, we wondered if we might be able to modify it so that it would be suitable for undergraduate business students and MBA students in bigger classroom settings at a large public university with different diversity factors. In fact, we reasoned that the inherently studentcentered perspective that is at the core of PROBE increased our chances of success in this endeavor, as PROBE "forces the class and organizations to deal with behavior, perceptions, assumptions, and values that diverge from the norm" (Nirenberg, 1994, p. 327). This very premise of the PROBE approach seemed to suggest that we might be able to successfully modify it to teach business majors and MBA students in larger classrooms (approximately 50) with students whose family backgrounds varied widely in terms of religion, financial standing, cultural background, and education. In fact, a significant portion of the students at this university are the first in their family to attend college, a high proportion are on financial aid and also work 20 hours or more to support their education, and many are from families who have recently immigrated to the U.S. Furthermore, we reasoned that some modifications to the original PROBE approach could be made to teach students more specifically about triple bottom line issues and concepts.

\section{PROBE AND THE TRIPLE BOTTOM LINE}

Nirenberg makes it clear that PROBE can be adapted to fit different course needs. As he writes, "The structure is flexible. The heart of the concept is in the real experiential environment that is created" (1994, p. 328). In our experience, we have found that PROBE is a flexible approach and that many of its key elements can be preserved when it is extended to teach triple bottom line concepts. However, there are several modficiations to the original PROBE methodology that we do recommend instructors consider. 
The PROBE approach is particularly apt for teaching triple bottom line concepts because at its heart, PROBE encourages students to act entrepreneurially and actually run their own "organizations." More than just developing a business plan, the PROBE approach provides a mechanism by which students can learn from their own business failures and successes as well as explore the emotional component inherent in entrepreneurial activities (Shepard, 2004; Tracy \& Phillips, 2007). By focusing on triple bottom line impacts with our PROBE modifications, we magnify the entrepreneurial aspects of the project and also focus students more specifically on social entrepreneurship. Therefore, the first, and most critical, modfication to the original PROBE model is that student teams be required to serve as social entrepreneurs, "individuals who develop economically sustainable solutions to social problems" (Tracey \& Phillips, 2007, p. 264). In essence, this requirement forms the heart of each student organization's mission.

As we have mentioned, the triple bottom line requires business ventures to be accountable not only for profit-related measures of success, but for social and environmental measures as well. As companies seek to identify and leverage business opportunities that also contribute to the social and environmental good, they have found themselves involved in a form of entrepreneurship.

When this entrepreneurial spirit is combined with triple bottom line expanded measures of success, it is commonly termed "social entrepreneurship." Social entrepreneurs identify market opportunities that allow them to generate earned income while also addressing social problems (Amin, Hudson, \& Cameron, 2002; Boschee, 2001; Hunt, 2000; Leadbeater, 1998; Oster, Massarsky, \& Beinhacker, 2004). To the extent that environmental or sustainability concerns are fundamentally social concerns, social entrepreneurship may cover a very wide range of issues, from creating wealth in underdeveloped communities to improving food quality or availability, to presevering the environment through sustainable business practices (Bornstein, 2004; Seelos \& Mair, 2005). At its heart, then, social entrepreurship is the process of creating organizations that have "the capacity to be both commercially viable and socially constructive" (Tracey \& Phillips, 2007, p. 265).

Sustainable business practices are those practices that "meet the needs of the present without compromising the ability of future generations to meet their own needs" (United Nations, 1987). This definition demonstrates that efforts aimed at achieving sustainability are basically a form of social entrepreneurship. In fact, this relationship has been so well established that a term has emerged for it: "environmental entrepreneur" or "ecopreneur" (Linnanen, 2002, p. 72). Indeed, the connection is very logical. Social entrepreneurs focus on social needs. Environmental entrepreneurs are a type of social entrepreneur focusing on social needs directly related to the natural environment and sustainable development. These ecopreneurs are a unique and vital type of social entrepreneur.

In addition to explicitly identifying student teams as social entrepreneurship ventures, we also recommend modifying the types of organizations students are required to build. As originally designed by Nirenberg (1994), students in a PROBE class are given the option to create either for-profit or non-profit groups. However, given the three-pronged focus of triple bottom line concepts on financial, environmental, and social results, it is important to emphasize to students the importance of finding a financially-viable business opportunity that addresses environmental and social concerns. Thus, in our modification of the PROBE project, we require students to specifically set profitability goals as part of their business plan. We have found it interesting that when they are in the project brainstorming phase, some student groups do tend to lose sight of the for-profit focus of this project, tending to assume that the project is simply meant to achieve outcomes related to the social and environmental good.

Although this pure focus on service might be appropriate in some circumstances, we find that the project is actually enhanced by the inclusion of a profit motive in several ways. Firstly, the profit motive prepares business students in a very practical way for the real world of business. Triple bottom line accountablity and social entrepreneurship is not just about doing good, but about making money while doing good (Boschee, 2001; Oster, et al., 2004; Tracey \& Phillips, 2007). We strive to teach them that regardless of how commited they are to their social and environmental vision, "only by operating profitably can social entrepreneurs engender sustainable social change" (Tracey \& Phillips, 2007, p. 267). Requiring students to focus on the profit motive therefore mimics real life business ventures. Secondly, requiring students to consider profitability increases the challenge associated with the project. Without a profit motive, students tend to focus on small scale, one-time event projects like park cleanups or fundraising events for particular charities. While noble in intent, we find that such projects are overly 
simplified and do not provide students wth an adequately complex challenge or learning opportunity. Thirdly, we find that the profit motive is a motivator for students in terms of the scope and quality of their work on the projects. Although in an ideal world, students would find grades alone to be a strong motivator, we find that adding the profit motive increases student enthusiasm for the project, adds a productive element of competition into the project, and helps to focus and direct student effort and attention to the project. This modification retains the essence of the PROBE approach and capitalizes on its flexibility. Therefore, we recommend that instructors require students to focus their "business plan" on developing for-profit project teams. Due to legal constraints, however, we then require that the students donate their profits to a non-profit entity.

A third modification to the original PROBE assignment we make is the requirement that students set social and environmental goals for their venture. We emphasize to students that it is not enough to merely make a profit, but to seek to improve social and environmental conditions in so doing. In our experience, combining all three goals in one project idea is by far the most challenging part of the project, but also the part that is most essential for a high quality, satisfying outcome. Students usually start by jumping right in and brainstorming various project ideas that quickly come to mind. These initial projects are usually somewhat limited in scope and often only accomplish one or two of the triple bottom line requirements. For example, students often discuss the idea of throwing a fundraising event for a local social services organization, and overlook the environmental impact of the proposed event. Similarly, initial ideas about environmentally-based projects often overlook the profit motive and the social impact. At this stage of the project, we have found it useful to guide students in their decision-making process.

We start by discussing the technique of brainstorming and then transition into an exercise in which the students identify as many as possible social and environmental problems facing the campus and local community. We then use this process to introduce the Nominal Group Technique (Delbecq, Van de Ven, \& Gustafson, 1975; Van de Ven \& Delbecqu, 1974; Woodman, 1981) and how it aids in decision-making. This process tends to be quite effective, because students are not only learning about two important decision-making techniques, but are also being encouraged to step back from focusing immediately on actual projects and instead discussing one or more social or environmental concerns that they feel passionately about and that may provide business opportunities. Thus, students are exposed to some of the strategic thinking and decision-making processes that are essential for successful ventures.

After agreeing on a project, students are then ready to start writing their business plans. The scope and detail included in these plans can vary depending on instructor goals and student abilites. Business plans may include mission statements and specific goals for each of the three triple bottom line outcomes, along with SWOT's, budgets, cost/benefit analyses, future projections, and any other requirements aligned with course goals. The business plan is a central component of the original PROBE methodology and even in its original form is a powerful teaching tool (Honig, 2004). However, with the modifications that we recommend, we have found that the entire process of choosing a project and writing the business plan is enhanced, as our modifications require students to think creatively and holistically about the role of business in society, foster innovation by identifying new niches, engage in complex decision making and planning, and finally put all of these ideas into clear, succinct, and persuasive writing.

A fourth change that we recommend to instructors seeking to use the original PROBE-approach to teach triple bottom line concepts is to provide more guidelines to student organizations (i.e., student teams) in terms of their fundraising. In the intial start-up phase of the student organizations, one of the main challenges students face is the dilemna over how to raise funds to cover their basic operating costs. In the original PROBE model, this entire process is left to the students, many of whom seek corporate sponsors for their start-up costs. For example, a student organization that formed an entertainment organization and threw a for-profit "rave" party relied on many corporate sponsors to not only donate funds, but adverstising, beverages, and even the space in which to host the event. However, we have found that students can benefit from instructors who talk about other types of funding sources and the complex issues inherent in raising funds. For example, students might want to take into account the mission and ethics of any possible donor organizations. Sources other than corporate donations might also be encouraged. Students might want to consider the pros and cons of making their own personal financial investments in their projects, the possibility of finding "angel investors" (often friends and family of students), and considering minigrant funding that is often available to students on campus. For example, on our campus, $\$ 80,000 /$ year is offered in 
grant money for students seeking to implement any green initiatives that target the university community. Similarly, deans are often willing to provide small grants and/or mini-loans for well-planned projects that have the potential to bring positive media attention to the College of Business and increase its visibility.

Related to this financial issue is the fifth modification we recommend, that of the criteria for project evaluation. For instructors seeking to apply PROBE to triple bottom line issues, we of course recommend that instructors hold students accountable for profit, social, and environmental goal attainment. This requirement provides a very interesting learning opportunity for students. We require that in their initial business plan, they grapple with how to objectively measure impacts that are by nature often difficult to quantify, and then measure their attainment in a concrete way throughout the project.

The five modifications we have recommended herein retain the integrity of the PROBE approach: to make the learning environment highly student-centered, to allow students to take ownership of their learning process, and to draw attention to the dynamics of effective teamwork. There is no limitation regarding what course material should or should not be covered when employing the PROBE methodology. Instructors can adapt this methodology to many different courses that are taught. As such, PROBE can be a very effective approach to use in teaching triple bottom line concepts. By making the modifications detailed above, the effectiveness of the PROBE approach can be used to help guide and strengthen the process of teaching students about social entrepreneurship and sustainability via an experiential-learning modality. The final product is a course which is delivered in an integrated manner such that the student is not aware of the strategic pedagogical thinking that went into designing the course.

\section{EXAMPLES OF TEACHING TRIPLE BOTTOM LINE CONCEPTS WITH PROBE}

In this section, we present some specific examples of how PROBE can be used to teach triple bottom line concepts. A PROBE approach to teaching can have a tremendous impact on student learning and can produce amazing results. For example, in one class, the entire class as a whole decided to dedicate themselves to address social and environmental issues associated with waste disposal. One team worked with the local government, local businesses, and the university community to put an educational and marketing program in place that encouraged individuals to recycle more at work and at home. At the end of the semester, the students presented their results, showing how they had made a positive impact on society (the local community) as well as the natural environment (in terms of waste reduction).

Another student team organized a community "re-cyclethon" at a local grammar school. This creative entrepreneurial effort raised awareness about recycling in young children as well as addressing the social issues of health and exercise. These students raised $\$ 3,000$ that was donated to a local non-profit organization that specialized in recycling. Although both organizations focused specifically on waste reduction through recycling, they each had to generate their own ideas and specific triple bottom line goals, formulate them into a plan of action, and work with all the stakeholders involved to move their plan forward. Stakeholders included local schools, government agencies, local businesses, and university officials. As with many of the triple bottom line PROBE projects we have facilitated, both of these ventures were a success and both received high-profile media coverage. Moreover, students developed a great deal of course-specific knowledge and skills in the process of executing their ventures.

In a different undergraduate class, another team also focused on recycling. However, this team focused on recycling as a social service. This team identified a social need for better community clean-up after weekend parties. The dirty red plastic cups used to hold beverages at these events would often be scattered all over lawns, streets, and sidewalks for days after a party, and sometimes would never be cleaned up by students. This litter problem was not only unsightly for visitors to our campus community, but a defilement to the environment. Furthermore, the particular red cups used were recyclable and represented an unexploited niche for recycling. To address these issues, the team worked with various partners to raise funds to purchase a fleet of recycling bins. Then they procured free advertising in the campus and local newspapers to drum up business for their party cup recycling venture. They then sold a "Red Cup Recycling Service" to the student community. Any group planning to have a party just called the team the day before. The team would bring over as many recycling bins over as the hosts estimated they might need for their event. Partygoers then had large, convenient receptacles for their used cups. 
The team would then pick up the filled bins the next morning and take them to the recycling center. This team raised enough money to cover all of their fuel costs, buy a full second fleet of recycling bins, and make a profit of several hundred dollars each. In fact, this team was so successful that they had several hosts continue calling them for services even after their class project was complete.

Several MBA student projects also warrant mention. One team identified a need to reduce reliance on commercial fertilizers and augment the earth's topsoil. Specifically, their goals included providing a social service by picking up food waste from local eateries, providing an environmental benefit by making compost to reduce reliance on commercial fertilizers, and making a profit by selling the compost they made. They worked together to form partnerships with local restaurants, whereby these restaurants threw their food waste into bins provided by the team. The team picked up the full food waste bins every evening at the close of business and brought them to a composting pile that the team developed on land donated by a local organization. Another organization donated several pounds of highest quality worms to speed the composting process. This project, currently in progress, projects that they will meet their financial goals by selling the compost to local businesses and homeowners.

These examples illustrate the potential scope and impact of successful Triple Bottom Line PROBE Projects. How an instructor will specifically design his or her course will depend on factors such as student backgrounds, breadth and depth of course material, level of student and instructor involvement desired (e.g., number of hours outside of classroom time dedicated to student projects), local environmental conditions (e.g., local organizations that can be used as resources and local needs related to social entrepreneurship and sustainability), and others. For example, in introductory courses, students may not come into a course with enough background to get up and running with their business plan right away. These students may need substantial guidance in terms of formulating their plans, or they may need a solid introduction to the nature of social entrepreneurship in the week prior to generating their central organizational purpose. On the other hand, if PROBE is implemented in a capstone or MBA course, students may have the background to independently write detailed business plans and engage in the project with relatively little instructor intervention.

We have successfully used this Triple Bottom Line approach to PROBE in introductory, upper-level, and graduate level courses. By integrating the modified PROBE approach into these courses, we offer evidence that it is indeed possible to weave social entrepreneurship principles through a broad variety of courses, as suggested by Tracey and Phillips (2007). However, where Tracey and Phillips (2007) suggest that requiring a business plan is one method of achieving this goal, we go beyond their suggestions by also requiring implementation of the plan and evaluation of the outcomes. The important thing to keep in mind when making these curriculum decisions is the goal of the program and the quality of work that can be reasonably expected. In an introductory course, the main impact of a PROBE project is to inspire, energize, and engage students in a particular area of study. In a more advanced course, the PROBE approach might be used as a way to assess student ability to apply an entire program of study to the real world. The key message is that all of these factors can be taken into consideration, and a unique and powerful learning experience can be created using the modified PROBE approach we describe here.

\section{ASSESSMENT}

At this point, an intrigued instructor might ask, "How can students be assessed when using this type of learning approach?" This is a vital question and Nirenberg dedicates a separate section of his 1994 article to addressing this topic. As he writes, "[f]irst, there are group-based assessments" (Nirenberg, 1994, p. 330). By this, Nirenberg means that teams are asked to reflect on course material and to explain how it is related to their organizations (i.e., teams). Organizations may bring up issues related to leadership, division of labor, team communication, how to acquire funding sources, how to manage a budget, how to promote their venture, how to measure the impact of their venture, or any other number of issues that are directly related to the course material. By this, the instructor makes the students accountable for the course material, while directing them to apply it to their specific experiences and challenges. This process allows analysis and problem solving to occur which is student-centered but which is grounded in the course material. Instructors can assess students on the quality of performing this process through written work, or through informal or formal oral presentations and discussions. For example, instructors may have student teams present their business plans to the class for constructive criticism and feedback early in the semester. Then, at the end of the semester, teams may present to what extent they achieved 
their outcomes, as well as what they learned about the process of being a team and implementing their project via direct application of course material. Lastly, as with most team projects, it is advisable for instructors to incorporate some form of a peer evaluation into the project to encourage accountability and participation from all team members.

"Second, there are two forms of individual assessment: quizzes and personal learning journals" (Nirenberg, 1994, p. 330). The quizzes are based on assigned class material. Employing an assessment technique such as quizzes encourages students to know the class material so they will be better prepared to apply it when performing as an organization. The structure of the quizzes is flexible according to instructor preference. Quizzes may or may not be timed, and could be written in true/false, matching, multiple choice, or even short essay format. Lastly, students write "personal learning journal reports about critical incidents in their experience" (Nirenberg, 1994, p. 331). These personal learning journal reports should be confidential between the instructor and each student. These journal reports allow students to review and analyze specific events or issues which are sensitive or which have particular meaning to them, while applying them to course concepts and theories (Nirenberg, 1994).

Given the assessment tools discussed above, the flexibility of PROBE again becomes apparent. Just as instructors should utilize its flexibility in applying it to the topics and goals of their courses, they should take advantage of the various assessment tools that can be used to meet their needs. Depending on the focus of one's course, the maturity level of the students, the assessment orientation of the instructor, and other factors, instructors should choose the combination of assessment tools that best accommodate their particular circumstances. This statement applies to courses focusing on triple bottom line concepts, as well as any other courses sharing a similar pedagogical thrust.

\section{CONCLUSION AND FUTURE DIRECTIONS}

Many instructors may find that they have already been using some of the techniques described here. In these cases, the technique may not be labeled "PROBE," but it may resemble the PROBE approach in some (or many) aspects. The unique contribution of PROBE, however, is that it effectively combines so many techniques into one overarching pedagogical approach. For example, many instructors may use group projects and/or problem solving discussions in their classrooms, however PROBE is unique in terms of the specific guidelines provided for instructors and students. In fact, every single part of the PROBE approach is centered around one goal: increasing student engagement through active learning. The consistency with which every single part of the PROBE approach adheres to this central goal is truly remarkable.

Given the power of this approach, it is interesting to consider the extent to which it has been adopted. For example, how many courses have been and are being taught using the PROBE technique or some modification of it? To what extent are these efforts successful? Unfortunately, the answers to these questions are not known. However, Nirenberg (1994) did make an important contribution in that his article formally explained how and why to use the PROBE approach so that others could take advantage of it. The original PROBE technique was developed with respect to teaching courses in organizational behavior, but it is clear that this technique can be adapted to other courses. Research assessing the spread of PROBE into other disciplines might be useful in guiding its importation into particular courses. For example, perhaps PROBE courses tend to center around certain topics, disciplines or geographical areas. Hopefully, these and other research questions will be answered as we continue to learn about the effectiveness of experiential learning.

We surmise that many courses focused on teaching social entrepreneurship in an experiential-learning context may be delivered in a manner that somewhat resembles the PROBE approach. For instructors of these courses, we hope that this article has provided you with some inspiration to fine-tune your approach. For others who have not implemented some of the ideas presented here, perhaps this article has provided you with the guidance necessary to introduce this methodology at your own institution. By committing students to their learning experience by placing them in distinct "organizations" with unique plans, and by directing these plans to address triple bottom line outcomes, instructors have a powerful teaching approach to utilize. 


\section{AUTHOR INFORMATION}

Michael J. Gundlach, Ph.D. is an Associate Professor of Management at California State University, Chico. He teaches and conducts research in the areas of human resource management and general management. His work has appeared in outlets such as Academy of Management Review, Journal of Management, Human Relations, and International Journal of Organizational Analysis.

Suzanne Zivnuska, Ph.D. is a Professor of Management at California State University, Chico. She teaches and conducts research in the areas of human resource management and general management. She has published in a variety of academic and practitioner journals including Journal of Applied Psychology, Leadership Quarterly, Journal of Organizational Behavior, and Human Relations.

\section{REFERENCES}

1. Amin, A., Hudson, R., \& Cameron, A. (2002). Placing the social economy. London: Routledge.

2. Borgaza, C., \& Defourny, J. (2001). The emergence of social enterprise. London: Routledge.

3. Bornstein, D. (2004). How to change the world: Social entrepreneurs and the power of new ideas. Oxford and New York: Oxford University Press.

4. Boschee, J. (2001). Eight basic principles for nonprofit enterpreneurs. Nonprofit World, July-August, 15 $-18$.

5. Cheit, E. (1985). Business schools and their critics. California Management Review, 27, 43 - 62.

6. $\quad$ Dees, J. G. (1998). Enterprising nonprofits. Harvard Business Review, 76(1), 54-65.

7. Delbecq, A. L., Van de Ven, A. H., \& Gustafson, D. H. (1975). Group Techniques for Program Planning: A Guide to Nominal, Group, and Delphi Processes. Glenview, IL: Scott, Foresman.

8. Gioia, D., \& Corley, K. (2002). Being good versus looking good: Business school rankings and the circean transformation from substance to image. Academy of Management Learning and Education, 1, 107 $-120$.

9. Hayes, R., \& Abernathy, W. (1980). Managing our way to economic decline. Harvard Business Review, $58,67-77$.

10. Honig, B. (2004). Entrepreneurship education: Toward a model of contingency-based business planning. Academy of Management Learning and Education, 3, 258 - 273.

11. Hunt, A. R. (2000). Social entrepreneurs: Compassionate and tough-minded. The Wall Street Journal, July 13, A27.

12. Leadbeater, C. (1998). The rise of the social entrepreneur. London: Demos.

13. Linder, J., \& Smith, H. (1992). The complex case of management education. Harvard Business Review, September/October, 16 - 33.

14. Linnenan, L. (2002). An insider's experiences with environmental entrepreneurship. Greener Management International, Summer 2002(38), 71-80.

15. Mitzberg, H., \& Gosling, J. (2002). Educating managers beyond borders. Academy of Management Learning and Education, 1, 64 - 76.

16. Nirenberg, J. (1994). An introduction to probe: Practical organizational behavior education. Journal of Management Education, 18, 324-331.

17. Oster, S. M., Massarsky, C. W., \& Beinhacker, S. L. (2004). Generating and sustaining non-profit earned income. A guide to successful enterprise strategies. San Francisco, CA: Jossey-Bass.

18. Paton, R. (2003). Managing and measuring social enterprises. London: Sage.

19. Pfeffer, J., \& Fong, C. (2002). The end of business schools? Less successs than meets the eye. Academy of Management Learning and Education, 1, 78 - 95.

20. Porter, L., \& McKibbin, L. (1988). Management education and development: Drift or thrust into the 21st century. New York: McGraw-Hill.

21. Rice, F. (1993). Who scores best on the environment. Fortune, July 26, 114 - 122.

22. Robbins, S. P., \& Coulter, M. (2007). Management $\left(9^{\text {th }} e d\right)$. Upper Saddle River, NJ: Pearson Prentice Hall.

23. Seelos, C., \& Mair, J. (2005). Social entrepreneurship: Creating new business models to serve the poor. Business Horizons, 48, 241 - 246. 
24. Shepard, D. A. (2004). Educating entrepreneurship students about emotion and learning from failure. Academy of Management Learning and Education, 3, 274 - 287.

25. Tracey, P., \& Phillips, N. (2007). The distinctive challenge of education social entrepreneurs: A postscript and rejoinder to the special issue on entrepreneurship education. Academy of Management Learning and Education, 6, $264-271$.

26. United Nations. (December 11, 1987). Report of the world commission on environment and development. Retrieved August 10, 2008, from http://www.un.org/documents/ga/res/42/ares42-187.htm

27. Van de Ven, A., \& Delbecqu, A. (1974). The effectiveness of Nominal, Delphi and Interacting group decision-making processes. Academy of Management Journal, 17, 605 - 621.

28. Woodman, R.W. (1981). Use of the nominal group technique for idea generation and decision making. Texas Business Executive, Spring, 50 - 53.

\section{NOTES}

